The impact of using smartphones on the academic performance of undergraduate students

Ifeanyi Peter Ifeanyi

Joshua Ebere Chukwuere

North-West University, South Africa

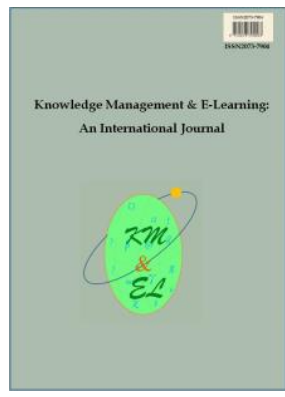

Knowledge Management \& E-Learning: An International Journal (KM\&EL) ISSN 2073-7904

Recommended citation:

Ifeanyi, I. P., \& Chukwuere, J. E. (2018). The impact of using smartphones on the academic performance of undergraduate students. Knowledge Management \& E-Learning, 10(3), 290-308. 


\title{
The impact of using smartphones on the academic performance of undergraduate students
}

\section{Ifeanyi Peter Ifeanyi}

Faculty of Economic and Management Sciences

North-West University, South Africa

E-mail: anyipeter123@gmail.com

\section{Joshua Ebere Chukwuere*}

Faculty of Economic and Management Sciences

North-West University, South Africa

E-mail: joshchukwuere@gmail.com

*Corresponding author

\begin{abstract}
This study investigated the impact of using smartphones on the academic performance of undergraduate students at the North-West University, South Africa. To determine the impact, this study deployed the quantitative research approach to collect data from 375 undergraduate students using questionnaires. It was found that most undergraduate students are using their smartphones to engage with fellow students and lecturers. It was also found that using smartphones distracts students from their studies in certain aspects. The results also showed the impact of using smartphones on students' academic capabilities and progression.
\end{abstract}

Keywords: Academic performance; Smartphones; Undergraduate students; Learning; South Africa

Biographical notes: Ifeanyi Peter Ifeanyi is a MCom Computer Science and Information Systems student in the Department of Information Systems, Faculty of Economic and Management Sciences, North-West University (NWU), South Africa. His research areas include smartphones, social media and many more.

Dr. Joshua Ebere Chukwuere $(\mathrm{PhD})$ is a Senior Lecturer at the Department of Information Systems, Faculty of Economic and Management Sciences, NorthWest University (NWU), South Africa. His research interests comprise culturetech, mobile banking, e-health, online banking, Internet of Things (IoT), smart city, technology acceptance, culture-oriented technology, e-learning, ehealth, social media and others.

\section{Introduction}

Smartphones are equipped with multimedia phone features, which include camera function, sound recording function, video function and many others. These features assist students to drive their learning process and dreams effectively. According to Kibona and 
Mgaya (2015), most smartphone- and recreational applications are addictive to both the higher level and lower level students in Tanzania, which, in turn, affects their academic performance. The applications mentioned included WhatsApp, Twitter and Facebook. Furthermore, some learning systems have emerged over the years and involve ubiquitous learning (u-learning), which is being powered by smartphone capabilities in the learning environment. According to Jung (2014), ubiquitous learning (u-learning) combines the characteristics of electronic learning (e-learning) and mobile learning (m-learning), in driving forward different forms of learning through the internet connection process in the 21 st century.

The mentioned forms of learning are all available on smartphones (e-learning and m-learning). Jung (2014) further states that u-learning is used to provide students with the right learning materials, depending on their situation. In this study, u-learning initiatives are supported by smartphones, which are used by the undergraduate students of the North-West University (NWU) in South Africa to access learning materials anywhere, anytime. The NWU's Mahikeng Campus is located in the heart of Mahikeng, the capital city of the North West Province, South Africa. At the Mahikeng Campus, a free wireless network is provided to students in some locations around the Campus. The Campus can be said to consist of students from middle- to lower-income families (Chukwuere, Mbukanma, \& Enwereji, 2017) or disadvantaged societies, and using smartphones is becoming a norm. Students who have smartphones connect easily to the wireless networks and gain limitless access to internet connections that are aimed at advancing students' learning experience and performance. Furthermore, the deployment of these internet (Wi-Fi) connections is aimed at increasing access to learning contents across the Campus and beyond. One of the thriving platforms to increase access to learning contents is e-Fundi. It is a course or learning management system used as a mechanism for learning engagement and communication and learning content delivery between the students and lecturers. e-Fundi helps the students to obtain their study materials, such as their lecture slides, to engage in online forums, to submit assignments, to write tests, quizzes and examinations, to communicate with lecturers and other students, and many more. It also possesses qualities of u-learning in the sense that, regardless of your geographical location within the nation, it can provide the student with the right learning materials for their academic work through smartphones. This means that e-Fundi is mobile-friendly, driving e-learning initiatives and, in doing so, increases access to learning contents for students on- or off-campus. Consequently, according to Joshua, Nehemiah, and Ernest (2015), e-learning is a borderless learning experience to increase tutors and (undergraduate) students' interaction as well as delivering effective teaching and learning contents across different platforms, such as smartphones and many more. Elearning platform promotes self-directed and progressive learning processes and access to high-quality learning contents (Weichhart, Stary, \& Appel, 2018; Day \& Erturk, 2017). Although, according to Guspatni (2018), sometimes the system can be difficult to navigate and use. To this study, the adoption of smartphone in classrooms promotes access to e-learning materials and opportunities.

The high levels of addiction to smartphones prove that it affects students' academic performance (Kibona \& Mgaya, 2015). This addiction causes some concerns as to whether the use of smartphones hampers or elevates the performance of students in general. Ezemenaka (2013) writes that the invention of mobile phone technology thrived with the quest for new knowledge changes and the desire among university students, and most of them are affected, including undergraduate students. This impact contributes to the students' academic performance both negatively and positively. With due consideration of the effect of smartphones on the lives of university students, this study 
aimed at investigating the impacts (positive and negative) of smartphones on the academic performance of undergraduate students. Furthermore, the study also investigated the impact of smartphones on undergraduate students' academic capabilities. Furthermore, to address the research objectives and tackling the problem statement, the following research questions were explored:

- What are the positive impacts of smartphone usage on the academic performance of undergraduate students?

- What are the negative effects of smartphone usage on the academic performance of undergraduate students?

- What are the effects of smartphones on undergraduate students' academic capabilities?

\section{Literature review}

Many researchers have, through recent years, pointed out the advantages and disadvantages of students using smartphones. It goes both ways, as the use of smartphones affects the students' lives not only academically, but also their personal lives. However, smartphone usage among undergraduate students of the NWU is yet unknown. Nevertheless, the use of smartphones has both positive and negative impacts on the students who use them.

\subsection{Role of smartphones in academic learning}

The role of smartphone and mobile technologies in education must not be ignored (Tikoria \& Agariya, 2017). Academic learning is now innovative as a result of smartphone and other media in promoting and advancing $21^{\text {st }}$ century needed skills and knowledge (Tulenko \& Bailey, 2013; Emerson \& Berge, 2018). Students have experiences of digital surroundings in a tactile and personal manner, which is brought about by some mobile devices, including tablets and smartphones (Cano, 2012). Mokoena (2012) argues that the use of smartphones by students improves collaborative learning through its connection to the internet. This statement implies that the use of smartphones drives students to be more engaged in learner-centred participation learning. This is a vivid indication on numerous supports that smartphones have brought to the students; it advances their understanding by increasing academic performance, social media participation and information sharing; it helps their social skills by giving them opportunities to seek academic assistance and support, and many more (Mokoena, 2012).

However, according to Kinsella (2009), the challenge of communication in lecture halls with students is solved due to the use of smartphones. Concomitantly, Mokoena (2012) states that group projects and/or work given to the students by their lecturers are easily and conveniently carried out with the aid of smartphones. This further shows that students are now able to record their lecturers' lessons and teachings in real time. This is done by recording information during lessons, which has been made possible by the sophisticated features available on smartphones. From different perspectives, people try to embrace the use of smartphones because it is no longer used as communication tools (calls and text messages) only, but also as tools for people's social and work lives and possibly a potential instrument in their academic lives (Cano, 2012). According to Buck, Melnnis, and Randolph (2013), Lytle (2012) reports that college students using the StudyBlue Flash Cards believed it assists them in memorising the key terminologies when preparing for their tests. The study further states that some students use iPhones for 
the Evernote Peek application, which serves as a note-taking cloud service, thereby giving them the opportunity to sort out their notes and transforming them into effective study materials.

With the evolution of smartphones, what the students do outside the classroom is very much the same as the work they do inside of the classroom. This observation is very important to the issue brought up in the study with regard to the responsibility or role of smartphones outside the premises of the school (university). It can be observed that students use their smartphones for various reasons at university without restrictions. Then, according to Vanwelsenaers (2012), students spend a considerable percentage of the 4.5 lesson hours using smartphones. Currently, collaboration is a key 21 st century skill that Singapore's teachers are trying to help their students learn. In addition, through the effective use of smartphones, students are engaged in dialogues and other collaborative activities, and this is an excellent illustration of how the smartphone facilitates conversation and information/content sharing (Buck et al., 2013; Vanwelsenaers, 2012).

\subsection{Portability of smartphones as a convenient means of learning for students}

Students happen to be interested in ways they can learn and at the same time have their attention captivated. They may be provided with autonomy over their educational experience (Buck et al., 2013) and access to standard learning contents and opportunities (Day \& Erturk, 2017). As a matter of fact, one of the most important features of the everevolving features of the smartphone is its small or rather portable size and its ability to be used not only in the classroom, but also outside the classroom (Mokoena, 2012). This offers an edge over the traditional platform for learning and teaching, which deals with books and chalk/marker boards behind the four walls of education institutions.

It was suggested by Ezemenaka (2013) that the use of internet-enabled phones has been on the rise in the 21 st century, and as a matter of fact is something that many cannot comprehend. Additionally, young people pay a great deal of attention to their internetenabled phones, also to what their peers think of them. As the mental effects of the use of smartphones are ever present in the lives of the users, there also exist other impacts caused by the continuous use of smartphones, and this has been identified to be an 'addiction'. Some psychologists, of recent, have issued cautions that cell phone users face the risk of being addicted to their phones. There are some medical concerns that have been raised in association with the use of smartphones; there also happens to be effects such as insomnia, anxiety, misery and others (Ezemenaka, 2013). All these effects usually develop when students find themselves without their cell phones. Ebiye (2015) listed the rudimentary utilities of smartphones, which comprise mobile teleconferencing, mobile audio and visual calls, as well as sending and receiving electronic mails. Then, according to Gowthami and VenkataKrishnaKumar (2016), they argue that the use of the internet is now a routine habit for students, as well as a medium that is used by students to search for information at anytime and anywhere. Based on all indications, the rate of smartphone penetration aids teaching and learning processes among students in developing societies through the use of internet connections. Smartphones and mobile technologies make access, exchange and mobility of information easier (Kent, 2016).

\subsection{Challenges involved in using smartphones and the effects accompanied with the use}

It appears that some students are able to accomplish tasks using smartphones at universities or classrooms, while in the case of others, the smartphone has become a 
potential form of distraction. Even the visibility and mere presence of a smartphone that is connected to the internet attract the attention of students and many adults, thereby diverting their focus and/or attention in class. Some students can 'switch' their focus between the smartphone as a form of entertainment device and at the same time, a learning platform (Barnwell, 2016). Additionally, smartphones could prove to be very important in the sense that it gives children, or in this case, students from different kinds of socioeconomic backgrounds, the same opportunity to access learning materials (digital-age information). However, the use of smartphones as a form of learning entails that students have to combine information and at the same time stay focused on their lesson or discussions in class. For students, who have low literacy skills and the steady urge to multitask on social media, blending the purposeful use of smartphones into classroom activity can be particularly challenging. Then, the main advantage of the tool tends to go to waste. There has been proportional growth in the use of mobile phones, and mobile phones are being overused (Baron, 2010). Smartphone encourages micro-learning for the employed and unemployed for advancement of knowledge and skills (Emerson \& Berge, 2018). Young people's use of smartphones invites the initiation of social circles; friendships are also initiated and destroyed. Romantic affiliations emerge from these social circles, which are often developed or established on the social and recreational websites, thereby probably leading to a shift in the relationship of users with their family members. Traditionally, friendships and social associations or connections were done in person; however, in the era of the evolving technological world of smartphones, they are being done over social networks and as a matter of fact have become the preferred platform to develop friendships. Friendships that are developed over social networks tend to be more recreational and are less based on educational purposes. Based on the previous sentence, it is a clear indication that less attention is given by the students to their academic work and activities. Some schools have decided to restrict the use of smartphones in classes or during lectures; the reason being that it enables the students to cheat during their examinations and/or tests (Buck et al., 2013). The easy internet access on smartphones enables students to easily look up their examination and/or tests questions online. The use of smartphones in this manner can cause the student to be somewhat relaxed about studying, as they can easily find the answers to their examinations or test questions online, thereby helping the students to pass their examination, but not helping them to have knowledge about what they are being taught by their lecturers. Consequently, the adoption of smartphones can be said to be driven by two properties of decadent and sensible dimensions.

In essence, it is no longer only a task-oriented technology for the purpose of productivity, but it is also an entertainment-oriented technology that is designed for pleasure. According to Chun, Lee, and Kim (2012), 18 to 20 persons tend to become thoroughly driven sentimentally in probing for fun and sensory stimulation when using a smartphone for entertainment purposes and pleasure, while they are likely to be judiciously persuaded to scrutinise cost benefits based on its performance when using smartphones for work (Chun et al., 2012). In this study, the effect of smartphones on academic performance or the learning of students is mixed with challenges that will be determined later in the study.

\section{Research methodology}

This study deployed a quantitative research method using questionnaires to collect data from undergraduate students at the NWU (Mahikeng Campus). A random sampling technique was used in selecting participants across all faculties of the Campus. 
There are 11499 students who were registered for the academic year of 2016 at the NWU, Mahikeng Campus. Within that number of students, there are 6,582 female students and male students are 4,917. A sample of 375 students was randomly chosen using the sample size determination method by Krejcie and Morgan (1970). 375 questionnaires were distributed, collected and analysed. The questionnaires were printed and handed out to students in their respective classrooms, at the cafeteria and many other places around the Campus (both in groups and individually).

The targeted group of students are the undergraduates of the NWU, Mahikeng Campus, South Africa, and the sample size used was 375, which included students from all faculties of the Campus, as the data collection was not limited to a specific faculty. All the distributed questionnaires were received back from the students, i.e. the return rate is $100 \%$. This was achieved through a consistent follow-up, reprinting and redistribution of questionnaires until the required number was achieved.

\section{Data analysis}

The analysis of findings in this study is a result of the collected questionnaires on the empirical investigation of the impacts of smartphones on the academic performance of undergraduate students at the NWU, Mahikeng Campus. The data analysis is arranged into four parts. Part 1 deals with the demographics; part 2 focuses on the positive impact of smartphone usage on the academic performance of undergraduate students; part 3 deals with the negative impact of smartphone usage on the academic performance of undergraduate students; while part 4 deals with the effects of smartphone usage on the academic capabilities of undergraduate students.

\subsection{Demographic information}

In the demographics section of the questionnaire, students were asked questions such as their gender, age range, and academic level. The reason behind the demographic questions is to determine or find out basic personal information of the respondents.

Table 1

Demographics

\begin{tabular}{llll}
\hline \multirow{2}{*}{ Construct } & & \multicolumn{2}{c}{ Responses } \\
& & N & Percent \\
\hline \multirow{2}{*}{ Gender } & Female & 236 & 62.9 \\
& Male & 139 & 37.1 \\
& $17-20$ & 42 & 11.2 \\
Age range & $21-24$ & 191 & 50.9 \\
& $25-28$ & 97 & 25.9 \\
& $29-32$ & 29 & 7.7 \\
\multirow{2}{*}{ Academic level } & 33 and above & 16 & 4.3 \\
& $1^{\text {st }}$ year & 40 & 10.7 \\
& $2^{\text {nd }}$ year & 115 & 30.7 \\
& $3^{\text {rd }}$ year & 121 & 32.3 \\
& $4^{\text {th }}$ year & 99 & 26.4 \\
\hline
\end{tabular}

Table 1 found that more of the respondents were female. The indication drawn from the findings shows that the study had more female respondents than male 
respondents. For the age range, the findings show that most of the respondents who filled out the questionnaire are in the age range of 21 to 24 years. This implies that the overall population was dominated by young students. To determine the academic level of the respondents, the findings show that most of the respondents were in their third year (see Table 1). This is an indication that most respondents come from the third-year undergraduate students who are more exposed to the digital world such as using smartphones.

\subsection{Analysis of positive impact of smartphone usage on students' learning}

The descriptive analysis in Part 2 aimed at analysing the positive impact of smartphones on the academic performance of the undergraduate students of the NWU, Mahikeng Campus. Below are the questions that provided the positive impacts:

Table 2

Internet access and getting help from classmates using smartphones

\begin{tabular}{llll}
\hline \multirow{2}{*}{ Construct } & & \multicolumn{2}{c}{ Responses } \\
& & N & Percent \\
\hline $\begin{array}{l}\text { Do you have internet access in } \\
\text { your classroom venues? }\end{array}$ & Yes & 125 & 33.3 \\
& So & 116 & 30.9 \\
$\begin{array}{l}\text { Can you easily reach your } \\
\text { classmates to get help from } \\
\text { them using a smartphone? }\end{array}$ & No & 134 & 35.7 \\
& Sometimes & 8 & 42.1 \\
\hline
\end{tabular}

Table 2 above shows that most undergraduate students often get internet access in their classes or lecture halls. The finding indicates that students use their smartphones even in class because of access to internet (WIFI) connections.

The use of smartphones is widely adopted by undergraduate students even as a learning aid in getting help from classmates. Table 2 also displays that most of the respondents' state that they get help from their friends in the classroom using smartphones. The findings show that students use their smartphones to reach their classmates for help with regard to their academics, meaning that smartphones are becoming academic-centric in developing countries.

The bar chart in Fig. 1 above shows that 197 (52.5\%) of the students believed that smartphones help them academically, while $143(38.1 \%)$ of the students ticked the 'frequently' option. As the finding suggests, participants are consistently using their smartphone in their educational learning.

The bar chart in Fig. 2 also shows that the majority of the students, 160 (42.7\%), are using their smartphones for the purposes of 'doing research', followed by the option of 'doing assignments', which had 73 (19.5\%). The next options, in descending order of frequency and percentage, were the 'downloading study material' option with $63(16.8 \%)$, the 'accessing lecture slides' option with 38 (10.1\%), the 'record live lectures' option with $25(6.7 \%)$, the 'watch tutorial videos' option with $15(4.0 \%)$, and finally the 'other' 
option with $1(0.3 \%)$. Judging from what has been indicated in Fig. 2, most students use their smartphones to perform different forms of educational activities, ranging from doing research, assignments and many more.

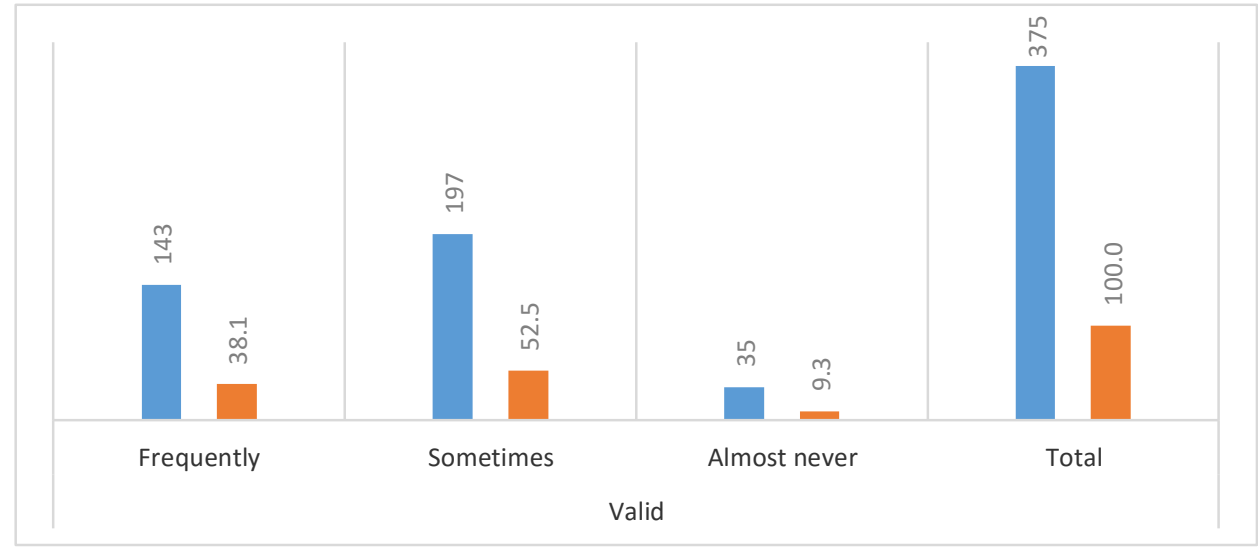

Fig 1. Use of smartphone for academic help

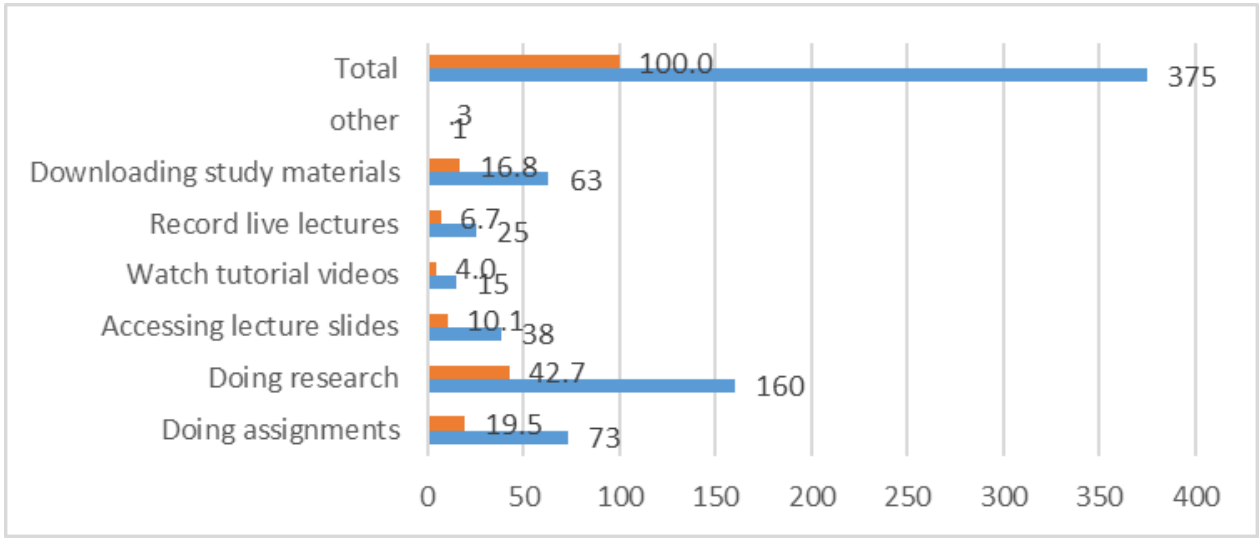

Fig 2. Educational activities performed with smartphones

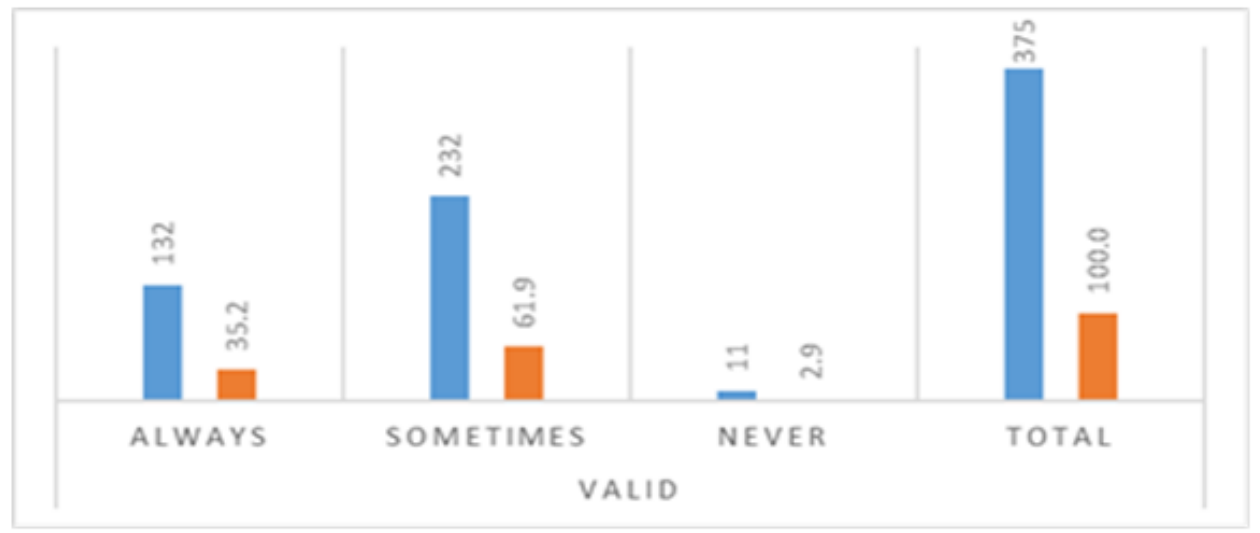

Fig 3. Perceived possibility to reach lecturers for help via smartphones 
Fig. 3 displays the analysis to the question: "Does your smartphone easily allow you to reach your teachers for help?" The majority of the students went with 'sometimes', and were $232(61.9 \%)$, followed by the 'always' option with $132(35.2 \%)$, and lastly the 'never' option with 17 (4.5\%). As this finding indicates, students use their smartphones to reach out to their lecturers for help in their academics.

The bar chart in Fig. 4 above represents the answers provided by the students to the question: "Has your academic performance increased with the use of smartphones?" Most of the students went with the 'partially' option, which had 287 (76, 5\%), followed by the 'no idea' option, with $42(11.2 \%)$, the 'no' option with $26(6.9 \%)$, and finally the 'yes' option with $20(5.3 \%)$. The finding indicates that students find smartphones effective in improving their academic performance.

According to Fig. 5, the bar chart above, 175 students (46.7\%) ticked the 'never' option, 169 students $(45.1 \%)$ went with 'Sometimes', and finally $31(8.3 \%)$ went with the last option, which was 'Yes'. As indicated above, lecturers use smartphones to aid teaching and learning.

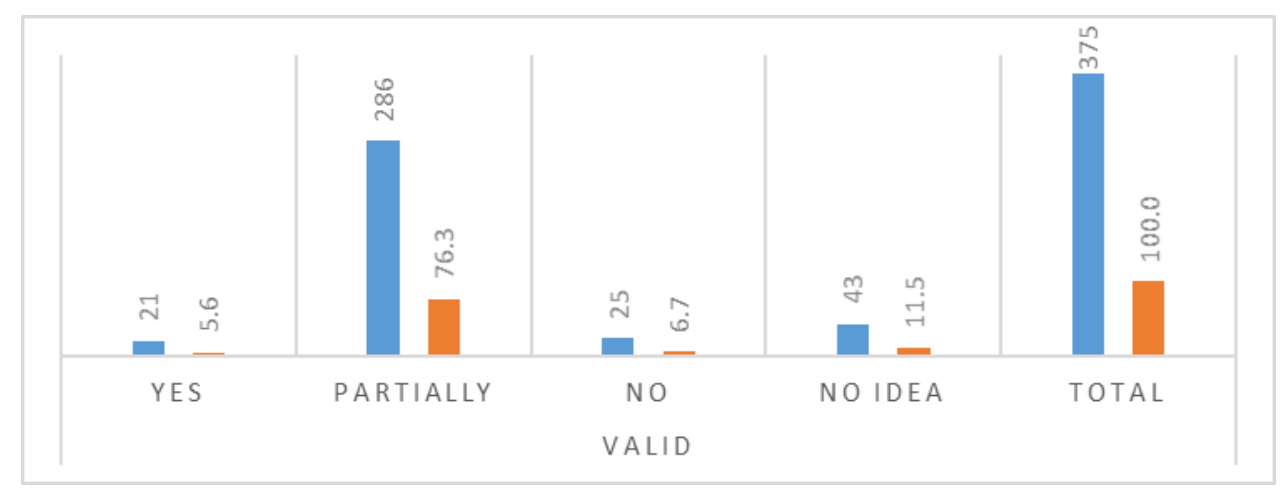

Fig 4. Perceived increase in academic performance with the use of smartphones

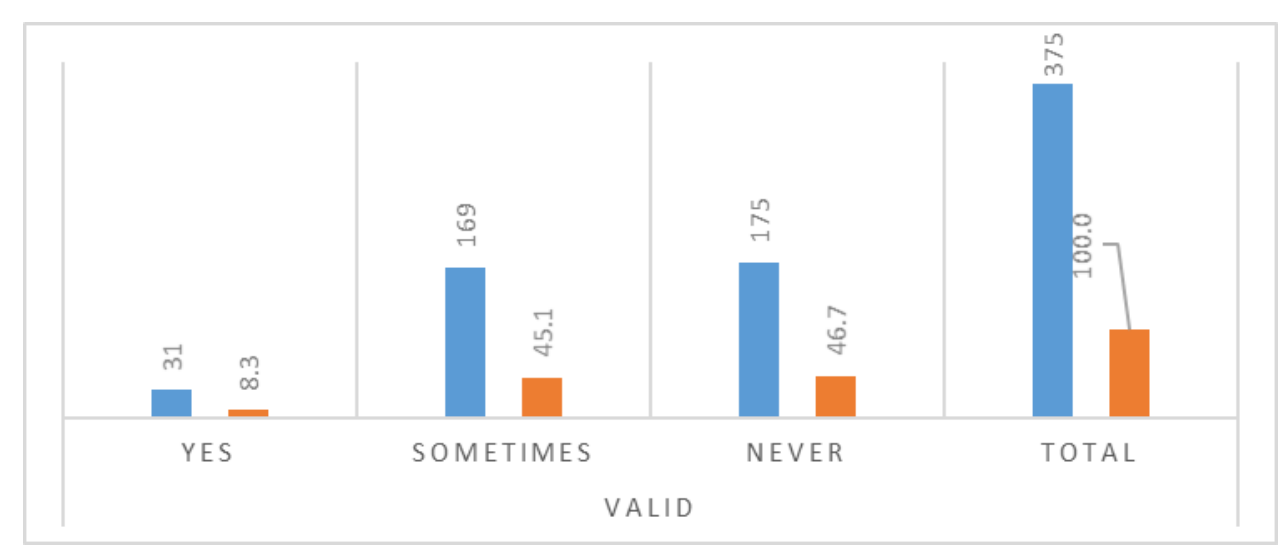

Fig 5. Perceived use of smartphone by lecturers to aid teaching 
The bar chart above in Fig. 6 presents the question: "Do you find smartphones helpful when you want to use calculators or dictionaries?" Most of the students went with the option 'sometimes' and were $268(71.5 \%)$, followed by $97(25.9 \%)$ students, and finally $10(2.7 \%)$ students. This indicates that students use their smartphones to perform calculations and make use of the dictionary.

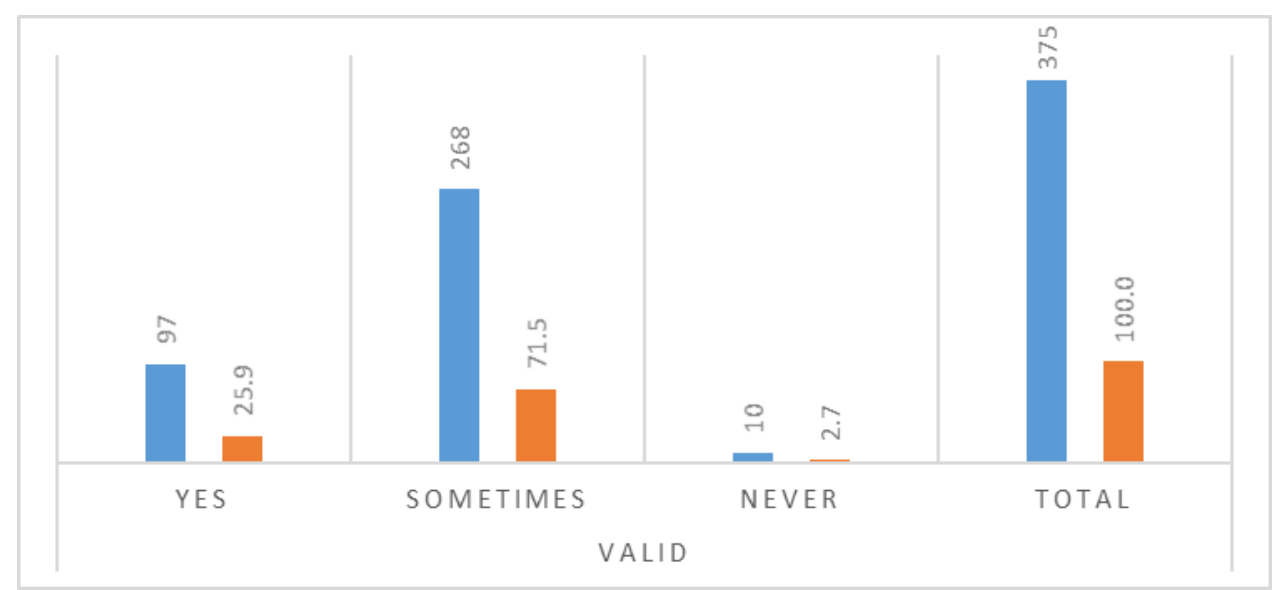

Fig 6. Perceived help of calculators and dictionary in smartphones

Fig. 7 answers the question "Does your access to the internet through your smartphone help you understand your lectures better?" According to the chart in Fig. 7, $259(69.1 \%)$ of the students went with 'sometimes', $104(27.7 \%)$ of the students went with the 'yes' option, while $12(3.2 \%)$ of the students went with the 'never' option. This indicates that students find their smartphones helpful in understanding the lectures as they are taught.

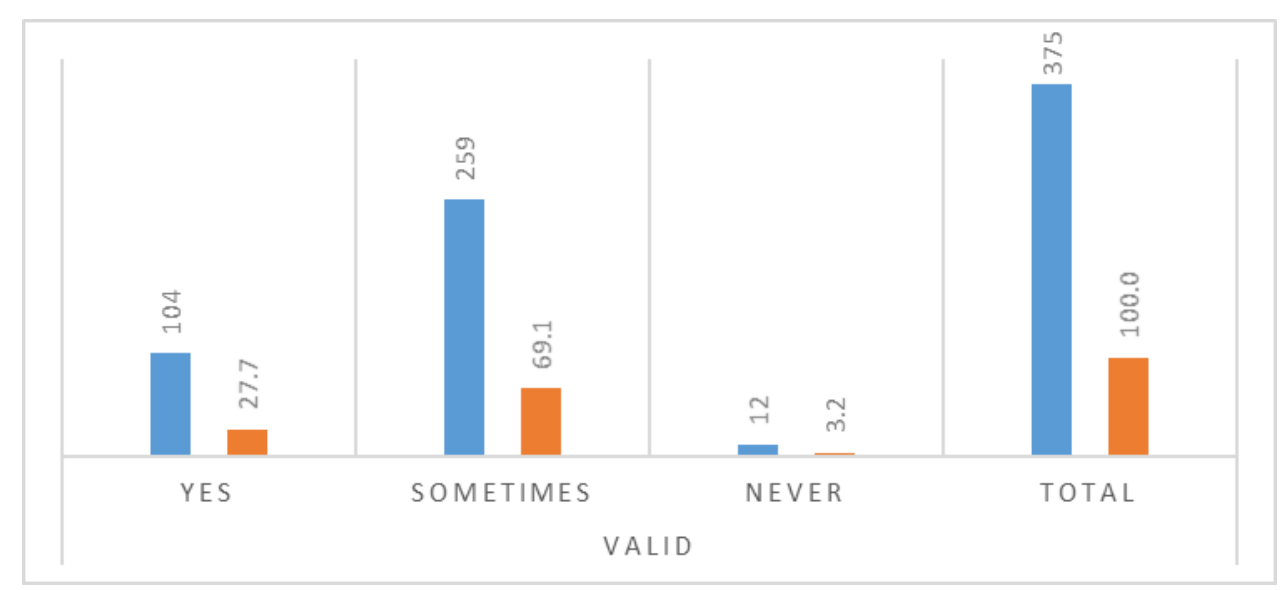

Fig 7. Perceived help for understanding lectures 
Using the bar chart above in Fig. 8, it is displayed that $185(49.3 \%)$ of the students 'sometimes' record/store lecture notes with their smartphone, $159(42.4 \%)$ students went with the 'yes' option, while 31 (8.3\%) went with the 'never' option. This indicates that students use their smartphones to record lecture notes and this will be of help to them when they want to study later.

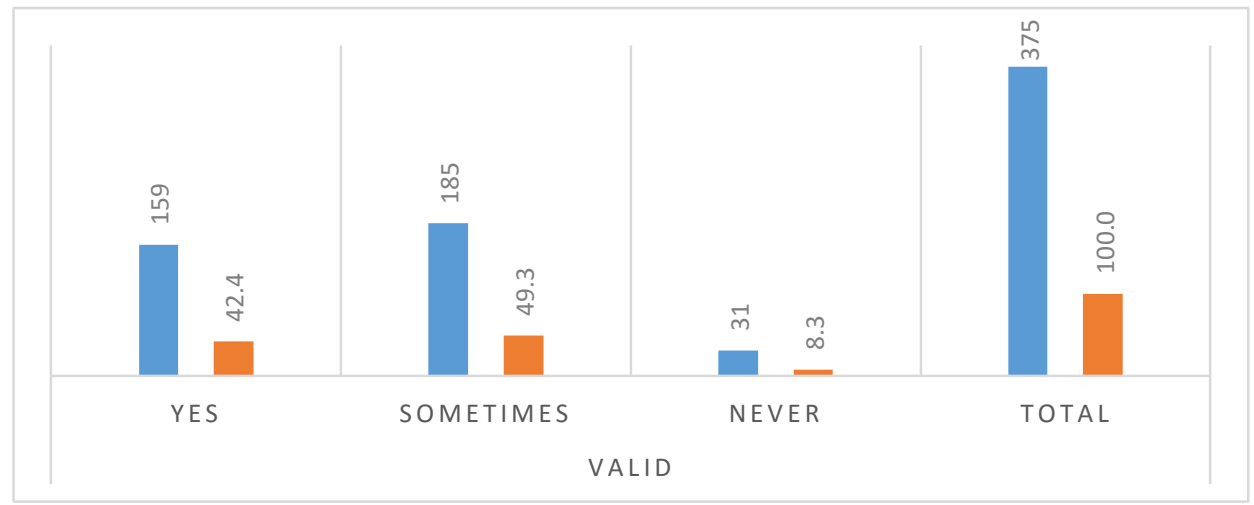

Fig 8. Perceived help for recording/storing lecture notes

\subsection{Analysis of the negative impact of smartphone usage on student learning}

In Table 3, the descriptive analysis is aimed at analysing the questions asked in relation to the negative impact of smartphones on the academic performance of undergraduate students of the NWU, Mahikeng Campus.

Table 3

Negative impacts

\begin{tabular}{|c|c|c|c|c|}
\hline No & Questions & Always/Yes & Sometimes & Never \\
\hline 1 & How often do smartphones distract students' learning in general? & $24.8 \%$ & $71.2 \%$ & $4.0 \%$ \\
\hline 2 & How often do you receive calls on your smartphone in class? & $18.9 \%$ & $61.6 \%$ & $19.5 \%$ \\
\hline 3 & $\begin{array}{l}\text { How often do you receive text messages on your smartphone } \\
\text { while in class? }\end{array}$ & $18.7 \%$ & $63.2 \%$ & $18.1 \%$ \\
\hline 4 & $\begin{array}{l}\text { Do you often engage in replying to text messages on your } \\
\text { smartphone while in class? }\end{array}$ & $12.5 \%$ & $69.3 \%$ & $18.1 \%$ \\
\hline 5 & $\begin{array}{l}\text { How often does your smartphone ring and end up disturbing the } \\
\text { class? }\end{array}$ & $17.1 \%$ & $62.4 \%$ & $20.5 \%$ \\
\hline 6 & $\begin{array}{l}\text { Do you always take pictures with your smartphone while lectures } \\
\text { are going on? }\end{array}$ & $10.4 \%$ & $52.3 \%$ & $37.3 \%$ \\
\hline 7 & Does your use of smartphones make you do less school work? & $24.3 \%$ & $56.3 \%$ & $19.5 \%$ \\
\hline 8 & Does your smartphone deprive you from getting enough sleep? & $30.9 \%$ & $58.4 \%$ & $10.7 \%$ \\
\hline
\end{tabular}

In Table 3 above, question 1 shows the finding that suggests that the use of smartphones causes distractions to the undergraduate students who use them. Question 2 indicates that most undergraduate students do receive calls while in classroom on their smartphone and this can be a distraction to their attention. In question 3, the findings show that students sometimes receive text messages while in class. The indication 
derived from the analysis above shows that the undergraduate students mostly receive text messages while in class and this can be a distraction to them.

Question 4 (Table 3) above shows that undergraduate students reply to text messages while in class and, as a matter of fact, it can be a distraction to the students. Judging from what has been indicated above in number 5, students have their phones ring in class, and this a distracting factor for the students.

The overall indication from question 6 above expresses that students take pictures with their smartphones while in class and this will divert their attention from what their lecturers are saying. Question 7 above indicates that the use of smartphones makes students do less school work and this can lead to a decrease in the success of their academic performance. Sleeping time is important to a student. However, according to question 8 , the findings indicate that the use of smartphones by the students deprives them of sleeping time and this can be quite detrimental to their study patterns or learning. The overall findings from Table 3 testify that the misuse of smartphones by undergraduate students causes distractions during class sessions.

The chart in Fig. 9 above depicts that 194 (51.7\%) of the respondents are 'not entirely' sure whether smartphones consume their time or not, while $111(29.6 \%)$ believe that it does and $70(18.7 \%)$ suggest that it does not consume their time at all. The findings indicate that using smartphones is a time-consuming factor for many students who use them.

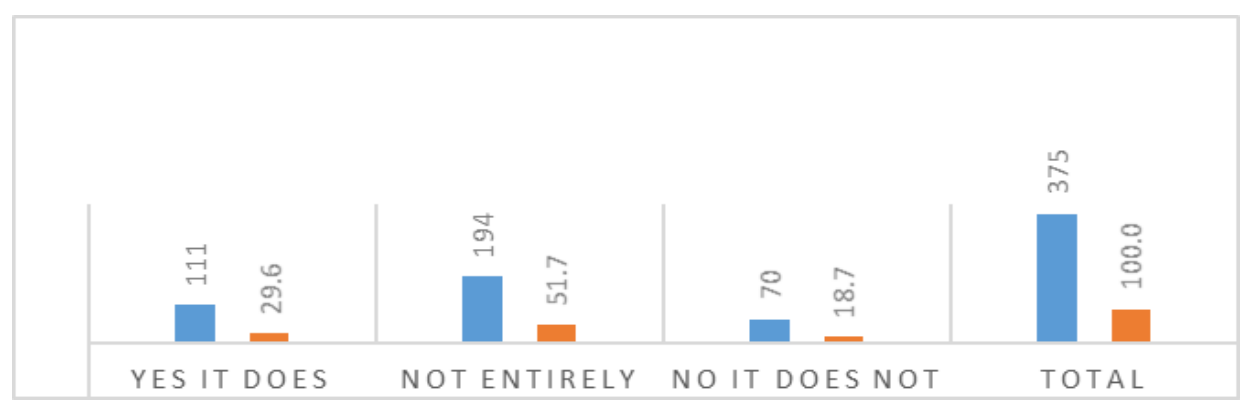

Fig 9. Use of smartphones consumes students' time

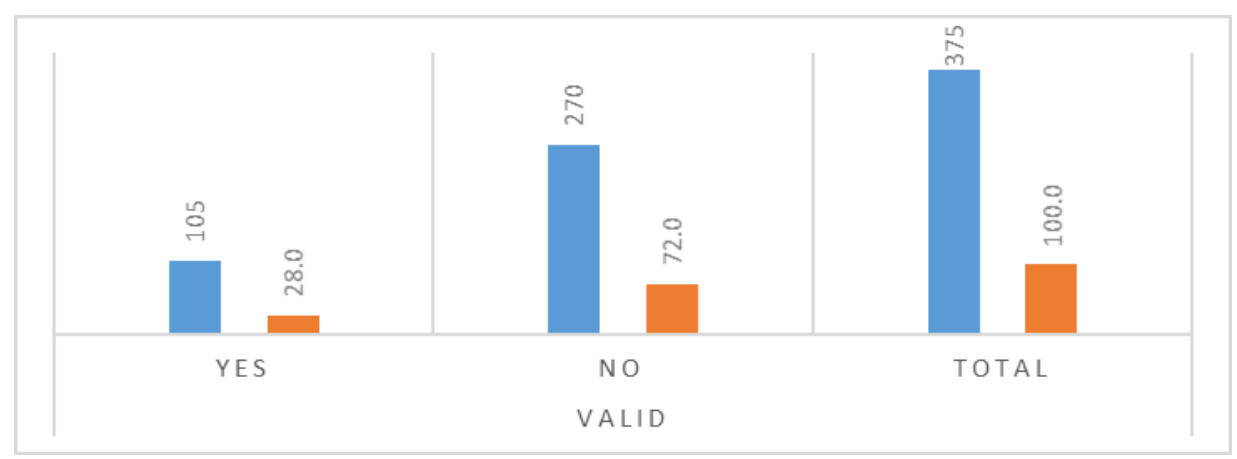

Fig 10. Perceived decrease in academic performance by smartphones

The chart above in Fig. 10 revealed that 270 (72.0\%) of the students suggest that smartphone usage does not decrease academic performance and $105(28.0 \%)$ believe that it does. According to their opinions, the use of smartphones decreases their performance academically. 


\subsection{Effects of using smartphones on the academic capabilities of undergraduate students}

The description analysis in Part 4 aimed at analysing the effects of using smartphones on the academic capabilities of undergraduate students of the NWU, Mahikeng Campus.

Fig. 11 presents the question: "Do you find it difficult to access academic materials on your smartphone?" The finding proves that 269 (71.7\%) of the respondents sometimes find it difficult to access academic materials on their smartphones, while 78 (20.8\%) have no challenge at all. The findings show that students find it difficult to access academic materials on their smartphones and this can affect the students' academic performance.

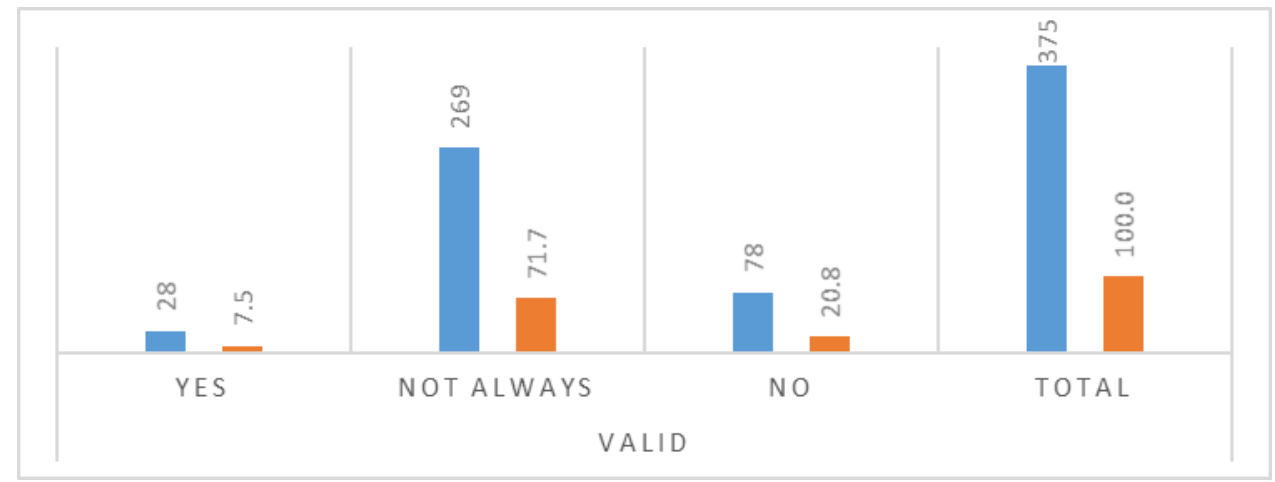

Fig 11. Perceived capability to access academic materials on smartphones

The chart above in Fig. 12 shows that 298 (79.5\%) students can accomplish their school work faster using smartphones, but 'not always', while $52(13.9 \%)$ can accomplish their school work faster using smartphones. This is an indication that students who use their smartphones accomplish school work faster than those without smartphones. The overall finding from this question proves that smartphone usage by undergraduate students is a welcome development improving academic work turnaround.

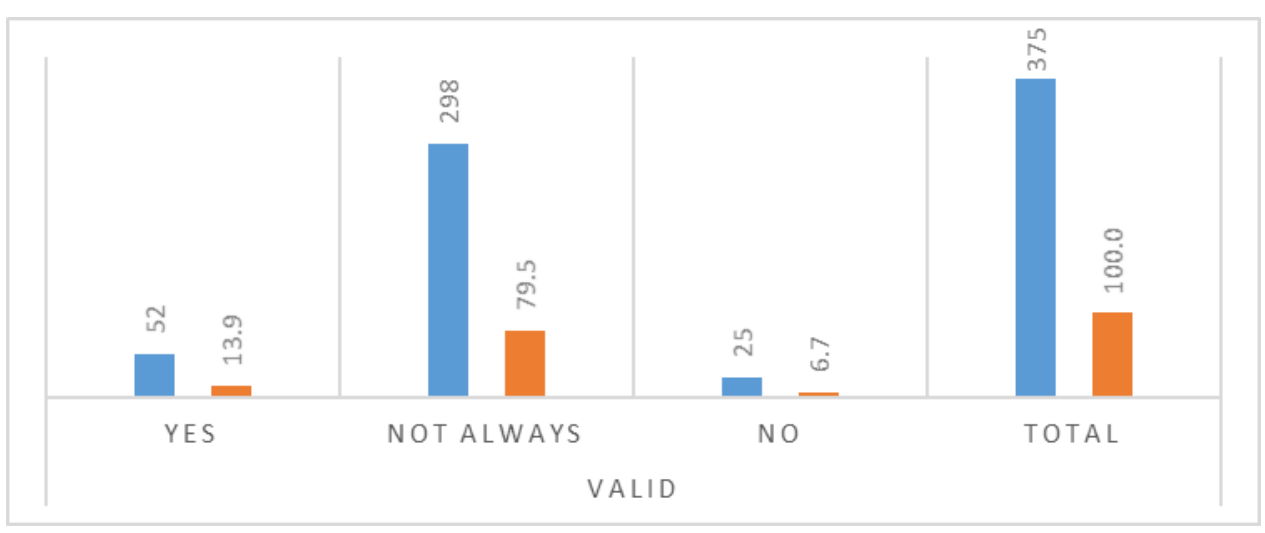

Fig 12. Perceived capability to accomplish school work faster while using smartphones

The above chart in Fig. 13 shows that the majority of the students said 'yes' when asked if, in general, the use of smartphones has instilled some academic knowledge in them. $117(31.2 \%)$ of the respondents do not believe that smartphones can instil new 
academic knowledge. This is an indication that smartphones can establish new academic knowledge in the undergraduate students.

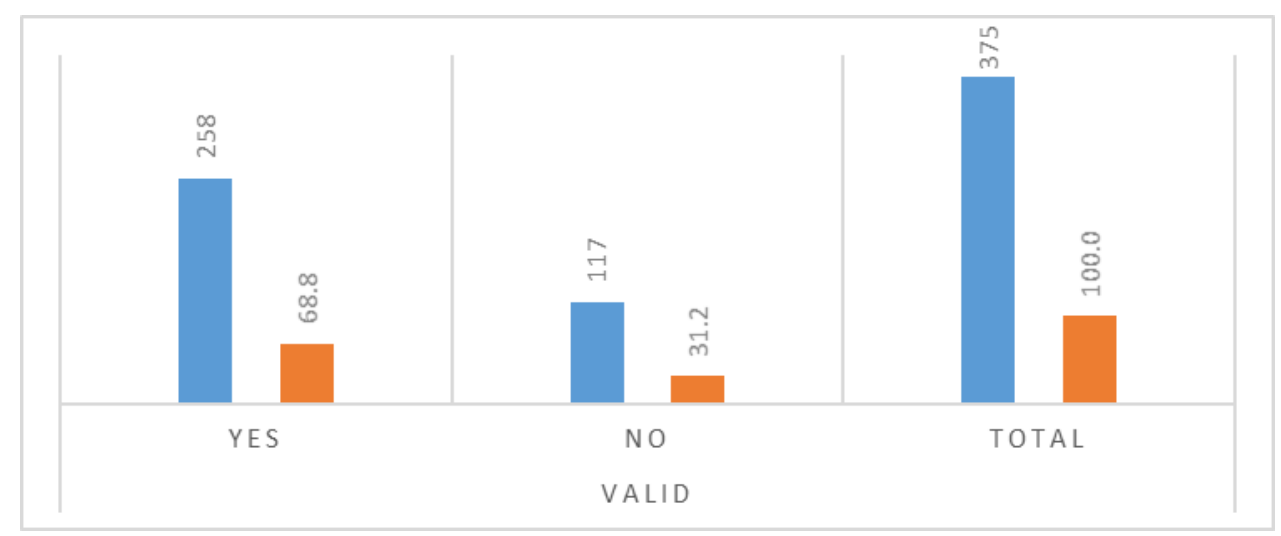

Fig 13. Perceived capability to use smartphones to instil academic knowledge

Fig. 14 presents that the majority, 231 (61.6\%), of the students suggested 'yes', that smartphones are advisable for undergraduate students and 144 (38.4\%) of the respondents do not want to see undergraduate students using smartphones. The findings suggest that many participants would like to see more undergraduate students using smartphones and to, a large extent, many oppose the recommendation. The overall response shows that smartphone usage among undergraduate students offers different kinds of opportunities and capabilities, as shown in Fig.11 to Fig. 14.

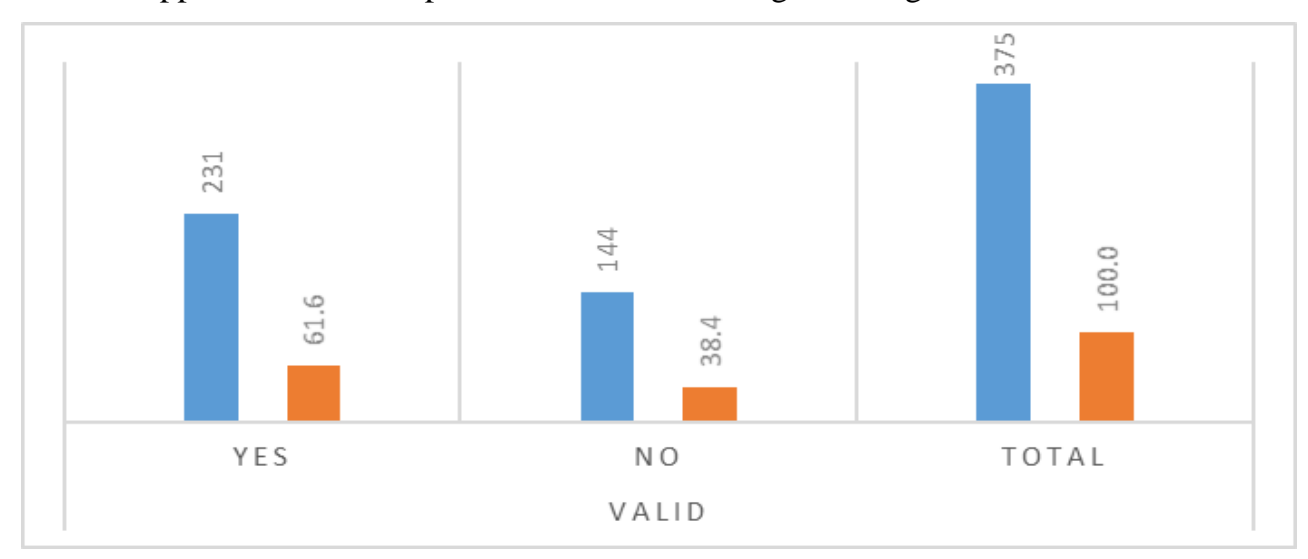

Fig 14. Advisability of using smartphones for undergraduate students

\section{Discussions}

The findings show that the male respondents contributed to $37.1 \%$ of the population, while female respondents contributed to $62.9 \%$. The age range of the participants was between 21 and 24 years, accounting for $50.9 \%$. The respondents were asked their faculty, and responses showed that Education and Training students were the most populated among the entire sample. It was also found that the majority of respondents speak Setswana (173) $46.1 \%$, with the lowest frequency of language use by the respondents coming from the Xitsonga tribe and the 'other' category, having $1.1 \%$ each. 


\subsection{Positive impact of smartphones on the academic performance of undergraduate students}

A cross-tabulation was performed between the gender of the students and smartphones distracting students from learning in general; it found that 50 of the male respondents find smartphones distracting and 43 were female students who suggest that smartphone usage is not distractive in general. According to Rouis, Limayem, and Salehi-Sangari (2011), smartphones equip students with access to internet connections, and this makes them feel the need sometimes to text their friends in class. Furthermore, a cross-tabulation was done between student faculty and the question: "Do you have internet access in your classroom venues?" The results show that Commerce students have more classroom venues that have internet access and the faculty with the least internet access is Human and Social Sciences, with eight of the students from the faculty saying that they have internet access in their classroom venues. In Fig. 4, students were asked whether their academic performance has increased with the use of smartphones; the results showed that $76.3 \%$ of the students stated that it has partially increased, $6.7 \%$ said that it has not increased and the other $5.6 \%$ suggested that their academic performance has definitely increased. Furthermore, $55.7 \%$ of the respondents get help from their classmates when seeking assistance; this finding is supported by Mokoena (2012) and Gowthami and VenkataKrishnaKumar (2016), who suggest that smartphone usage by students increases collaborative activities, information sharing, academic assistance and support from each other. Fig. 1 shows that 'sometimes' (52.5\%) and 'frequently' (38.1\%) using smartphones assists respondents academically. Positively, Fig. 2 highlights that the use of smartphones assists students in many ways, including doing research (42.7\%), doing assignments (19.5\%), accessing lecture slides (10.1\%) and many more. Furthermore, Fig. 3 proves that sometimes respondents reach out to their lecturers via smartphones. All the findings, including Fig. 4, 5, 6, 7 and 8, show that the use of smartphones by undergraduates benefits them academically in that it increases their performance, even though it is not in a huge way, but it increases nonetheless.

\subsection{Negative impacts of smartphone usage on the academic performance of undergraduate students}

There are negative impacts of social networks on the academic performance of students (Rouis et al., 2011). The correlation that was found displayed that relationships exist between the age range of the students and how often they receive calls on their smartphones while in class. The finding shows a positive relationship between the two variables, which means that the ages of the students have a significant impact on how often they receive calls on their smartphones in a classroom. In the descriptive statistics, under Table 3, question 1 proves that sometimes $(71.2 \%)$ suggests that they are distracted using smartphones in general, while a higher percentage of the students indicated that they sometimes $(61.6 \%)$ receive calls while in class, with $18.7 \%$ going with the 'always' option. Receiving and answering calls cause distractions (Rouis et al., 2011). In question $3,18.1 \%$ of the students never receive text messages on their smartphones and $63.2 \%$ of the students 'sometimes' receive text messages. The finding also shows that $69.3 \%$ of the respondents 'sometimes' reply to text messages in classrooms. Nonetheless, a crosstabulation shows that the use of smartphones impacts more on the sleeping patterns of the female students than their male counterparts. Because of these mentioned distractions, some schools have restricted the use of smartphones in classes or during lectures (Buck et al., 2013). 
The study further depicted in Table 1 question 5 that $62.4 \%$ of the respondents' smartphones ring, which ends up disturbing other students in class, while $17.1 \%$ of responses differ. Furthermore, many (52.3\%) students take pictures with their smartphone while in lectures. Moreover, as seen in Table 3 question 7, it has been proved that $56.3 \%$ of the participants engage in less school work because of smartphones. Additionally, a question was asked whether their use of smartphones causes them to not get enough sleep, and $58.4 \%$ of the participants are distracted. Smartphone usage consumes participants' time, with $29.6 \%$ of the students in support. Overall, the use of smartphones decreases academic performance, as $72.0 \%$ suggested. This implies that many of the participants are negatively affected by smartphone usage because they are mostly distracted in one way or the other while using smartphones. According to Baron (2010), the growth in the use of mobile phones causes mobile phones to be overused. The findings are counter to Mokoena (2012), who believed that smartphones improve the lives and activities of the users and increase collaboration, support and information sharing. Nonetheless, the effective use of smartphones positively affects a user.

\subsection{Effects of smartphones on academic capabilities of undergraduate students}

The descriptive analysis for the questions under this part showed that a greater number of students find it convenient to access their academic materials on their smartphones. This is in accordance with what Mokoena (2012) said; one of the most important features of the ever-evolving features of the smartphone is its small or rather portable size and its ability to be used not only in the classroom, but also outside the classroom. Crosstabulation was done between the students' year of study and the question: "Do you find it convenient to access academic materials on your smartphone?" The result shows that the second-year students found it more convenient to access academic materials on their smartphones, while 35 of the students stated that they find it convenient. Furthermore, the second-year students have the largest number of students who find it convenient to access their academic materials on their smartphone, with 17 of the second-year students saying that they do not find it convenient while 63 sometimes find it convenient. The overall findings concur with Al-Tarawneh (2014), who noted that positive contributions of smartphones towards students give them the ability to obtain academic support and assistance.

Furthermore, a correlation was developed in order to determine the relationship between students' year of study and the question" "In general, would you say that your smartphone has instilled academic knowledge in you?" The results showed that there is a positive relationship between the variables just mentioned. The correlation coefficient was shown as 0.185 . In addition, it showed that the student's year of study has a significant impact on the smartphone instilling academic knowledge in the students. The finding is also backed by data analysis, which shows that $68.8 \%$ of the students believed that smartphone usage instilled academic knowledge in them. Based on this, $61.6 \%$ of the respondents believe that smartphone usage should be encouraged at undergraduate level. The encouragement should come from fellow students, lecturers, parents, educational institutions, sponsors and many more. The findings show that smartphone usage by undergraduate students offers positive capabilities to the users. These capabilities are sets of encouragement in the adoption of smartphones for academic purposes for undergraduate students. However, according to Ezemenaka (2013), the invention of mobile phone technology thrives and brings in attitudinal changes among university students and most of them are affected, including undergraduate students. 


\section{Conclusions and recommendations}

In the literature review, important ideas were raised, which pointed out the positive and the negative impacts of the use of smartphones on the academic performance of undergraduate students. Gowthami and VenkataKrishnaKumar (2016) argue that the use of the internet is now a routine for people and also a medium that is used by the students to search for information at anytime and anywhere. This is a clear indication that college students now turn to smartphones to help them carry out academic activities. Even as the use of smartphones is common among college students or, in this case, undergraduate students, there lie with it some factors that are detrimental to the increase of the academic performance of students who use them (Table 3). However, the positive aspects of smartphones can improve the performance of undergraduate students if used well.

As per the findings that have been discussed above, there are a few recommendations that are made for consideration. They are as follows:

- Students said that they find smartphones helpful in keeping in contact with their lecturers. Furthermore, a higher percentage of the students found smartphones convenient in accessing their academic materials. In light of this, it is recommended that lecturers should communicate more with the students through this medium. This could be achieved by creating chat groups that can help every one of the students and lecturers stay connected in order to share information.

- According to the findings in relation to social networks, students visit the Facebook social network and WhatsApp more. Lecturers should therefore create profiles on Facebook or Facebook pages and WhatsApp groups dedicated to the modules they teach. This Facebook page and WhatsApp group will be a platform where the lecturers can post notes for download, notices and also discussions related to their lessons and module/s.

- Academic institutions should also implement programmes that can restrict students from using social network sites and applications while attending lectures.

- Lastly, even though a higher percentage of the students said that they do not receive calls while in class, it is recommended that the students are only allowed to use their smartphones when the lecturer tells or recommends them to do so; for example, to access their academic materials or something of the sort.

In conclusion, the findings show that there are many ways that smartphones affect the academic lives of the undergraduate students at the North-West University. In literature studies, there were arguments made for and against the impacts that smartphones have on the academic performance of students. This study can conclude with the fact that using smartphones made an impact on students both positively and negatively. Then, it will be highly beneficial if there could be more research carried out in developing countries on how students use smartphones to increase their academic performance, how low-income families or communities have impacts on students' usage of smartphones and the impact of smartphones on students attending classes and other academic related activities. This study presents an in-depth understanding on the effects of smartphones on undergraduate students in a developing country. The findings show that undergraduate students, in general, need to understand that smartphones improve their social and academic lives and it can also cause decreased performance in academic studies. However, the effective use of smartphones brings in more advantages than disadvantages to undergraduate students' lives. The results of this study will enlighten undergraduate students on the effects of using smartphones for multiple aspects. 


\section{References}

Al-Tarawneh, H. A. (2014). The influence of social networks on students' performance. Journal of Emerging Trends in Computing and Information Sciences, 5(3), 200-205.

Barnwell, P. (2016). Do smartphones have a place in the classroom? The Atlantic. Retrieved from http://www.theatlantic.com/education/archive/2016/04/dosmartphones-have-a-place-in-the-classroom/480231/

Baron, N. S. (2010). The dark side of mobile phones. Department of Language and Foreign Studies, American University. Retrieved from https://auislandora.wrlc.org/islandora/object/auislandora\%3A65410/datastream/PDF/ view

Buck, J. L., McInnis, E., \& Randolph, C. (2013). The new frontier of education: The impact of smartphone technology in the classroom. In Proceedings of ASEE Southeast Section Conference: American Society for Engineering Education.

Cano, E. V. (2012). Mobile learning with Twitter to improve linguistic competence at secondary schools. New Educational Review, 29(3), 134-147.

Chukwuere, J. E, Mbukanma, I., \& Enwereji, P. C. (2017). The financial and academic implications of using smartphones among students: A quantitative study. Journal of Economics and Economic Education Research (JEEER), 18(1): 5.

Chun, H., Lee, H., \& Kim, D. (2012). The integrated model of smartphone adoption: Hedonic and utilitarian value perceptions of smartphones among Korean college students. Cyberpsychology, Behavior, and Social Networking, 15(9), 473-479.

Day, S., \& Erturk, E. (2017). e-Learning objects in the cloud: SCORM compliance, creation and deployment options. Knowledge Management \& E-Learning (KM\&EL), 9(4), 449-467.

Ebiye, E. V. (2015). Impact of smartphone and tablets on the information seekingbehaviour of medical students and staff of Niger Delta University Bayelsa State - Nigeria. Library Philosophy and Practice (e-journal). Paper 1288.

Emerson, L. C., \& Berge, Z. L. (2018). Microlearning: Knowledge management applications and competency-based training in the workplace. Knowledge Management \& E-Learning (KM\&EL), 10(2), 125-132.

Ezemenaka, E. (2013). The usage and impact of Internet enabled phones on academic concentration among students of tertiary institutions: A study at the University of Ibadan, Nigeria. International Journal of Education and Development using Information and Communication Technology (IJEDICT), 9(3), 162-173.

Gowthami, S., \& VenkataKrishnaKumar, S. (2016). Impact of smartphone: A pilot study on positive and negative effects. International Journal of Scientific Engineering and Applied Science (IJSEAS), 2(3), 473-478.

Guspatni, M. (2018). Students' activities in, perceptions of and expectations for elearning: A case in Indonesia. Knowledge Management \& E-Learning (KM\&EL), 10(1), 97-112.

Joshua, C. E., Nehemiah, M., \& Ernest, M. (2015). A conceptual culture-oriented elearning system development framework (e-LSDF): A case of higher education institutions in South Africa. International Journal of Trade, Economics and Finance, 6(5), 259-265.

Jung, H. J. (2014). Ubiquitous learning: Determinants impacting learners' satisfaction and performance with smartphones. Language Learning \& Technology, 18(3), 97119.

Kent, M. (2016). Adding to the mix: Students use of Facebook groups and blackboard discussion forums in higher education. Knowledge Management \& E-Learning, 8(3), 444-463.

Kibona, L., \& Mgaya, G. (2015). Smartphones' effects on academic performance of 
higher learning students. A case of Ruaha Catholic University - Iringa, Tanzania. Journal of Multidisciplinary Engineering Science and Technology (JMEST), 2(4), 777-784.

Kinsella, S. (2009). Many to one: Using the mobile phone to interact with large classes. British Journal of Education Technology, 40(5), 956-958.

Krejcie, R. V., \& Morgan, D. W. (1970). Determining sample size for research activities. Educational and Psychological Measurement, 30(3), 607-610.

Lytle, R. (2012, September 21). 5 apps college students should use this school year. $U . S$. News \& World Report. Retrieved from http://www.usnews.com/education/bestcolleges/articles/2012/09/21/5-apps-collegestudents-should-use-this-school-year

Mokoena, S. (2012). Smartphones and regular cellular phones: assessing their impact on students' education at the University of Zululand. Doctoral dissertation, University of Zululand.

Rouis, L., Limayem, M., \& Salehi-Sangari, E. (2011). Impact of smartphone usage on students' academic achievement: Roles of self-regulation and trust. Electronic Journal of Research in Educational Psychology, 9(3), 961-994.

Tikoria, J., \& Agariya, A. K. (2017). ICT enabled classroom effectiveness scale development and validation: A case of multi-campus university. Knowledge Management \& E-Learning (KM\&EL), 9(1), 111-127.

Tulenko, K., \& Bailey, R. (2013). Evaluation of spaced education as a learning methodology for in-service training of health workers in Ethiopia. Knowledge Management \& E-Learning (KM\&EL), 5(3), 223-233.

Vanwelsenaers, M. (2012). Students using their own technology device in the classroom: Can "BYOD" increase motivation and learning. Master thesis, Northern Michigan University, USA.

Weichhart, G., Stary, C., \& Appel, M. (2018). The digital Dalton Plan: Progressive education as integral part of web-based learning environments. Knowledge Management \& E-Learning (KM\&EL), 10(1), 25-52. 